\title{
INFINITELY MANY SOLUTIONS FOR KIRCHHOFF TYPE PROBLEMS
}

\author{
YIWEI YE
}

\begin{abstract}
This paper is devoted to the study of infinitely many solutions for a class of Kirchhoff type problems on a bounded domain. Based on the Fountain Theorem of Bartsch, we obtain the multiplicity results, which unify and sharply improve the recent results of $\mathrm{He}$ and Zou [X. He, W. Zou, Multiplicity of solutions for a class of Kirchhoff type problems, Acta Math. Appl. Sin. (Engl. Ser.) 26 (2010) 387-394].
\end{abstract}

Mathematics subject classification (2010): 35J60, 35J25.

Keywords and phrases: Kirchhoff type problems, critical point, Cerami condition, Fountain theorem.

\section{REFERENCES}

[1] C.O. Alves, F.J.S. CorrêA, T.F. MA, Positive solutions for a quasilinear elliptic equation of Kirchhoff type, Comput. Math. Appl., 49 (2005), 85-93.

[2] B. CHENG AND X. WU, Existence results of positive solutions of Kirchhoff type problems, Nonlinear Anal., 71 (2009), 4883-4892.

[3] X. HE, W. Zou, Infinitely many positive solutions for Kirchhoff-type problems, Nonlinear Anal., 70 (2009), 1407-1414.

[4] X. HE, W. Zou, Multiplicity of solutions for a class of Kirchhoff type problems, Acta Math. Appl. Sin. (Engl. Ser.), 26 (2010), 387-394.

[5] L. JeAnJEAn, On the existence of bounded Palais-Smale sequences and application to a LandesmanLazer-type problem set on $\mathbb{R}^{N}$, Proc. Roy. Soc. Edinburgh Sect. A, 129 (1999), 787-809.

[6] R. KAJIKIYA, A critical point theorem related to the symmetric mountain pass lemma and its applications to elliptic equations, J. Funct. Anal., 225 (2005), 352-370.

[7] S. LIU, On superlinear problems without the Ambrosetti and Rabinowitz condition, Nonlinear Anal., 73 (2010), 788-795.

[8] T.F. MA, J.E. MuÑoz Rivera, Positive solutions for a nonlinear nonlocal elliptic transmission problem, Appl. Math. Lett., 16 (2003), 243-248.

[9] A. MaO, Z. Zhang, Sign-changing and multiple solutions of Kirchhoff type problems without the P.S. condition, Nonlinear Anal., 70 (2009), 1275-1287.

[10] K. Perera, Z. Zhang, Nontrivial solutions of Kirchhoff-type problems via the Yang index, J. Differential Equations, 221 (2006), 246-255.

[11] J.-J. SUN, C.-L. TANG, Existence and multiplicity of solutions for Kirchhoff type equations, Nonlinear Anal., 74 (2011), 1212-1222.

[12] M. WiLlem, Minimax Theorems, Birkhäuser, Boston, 1996.

[13] K. Yosida, Functional Analysis, Springer-Verlag, Berlin, 1980.

[14] Z. Zhang, K. Perera, Sign changing solutions of Kirchhoff type problems via invariant sets of descent flow, J. Math. Anal. Appl., 317 (2006), 456-463. 